\title{
Barriers, needs and potential solutions to reducing vulnerability to global environment change for least developed countries in the Asia-Pacific Region
}

M. Alimullah Miyan a,Natasha Kuruppu ${ }^{\mathrm{b}}$, Opha Pauline Dube ${ }^{\mathrm{c}^{*}}$, Mohammed Ataur Rahman $^{\mathrm{d}}$, Tanvir Dewan, Reenate Willie ${ }^{\mathrm{f}}$ and Shohidullah Miah ${ }^{\mathrm{g}}$

a South Asian Disaster Management Centre (SADMC), IUBAT-International University of Business Agriculture and Technology, Dhaka 1230, Bangladesh

b United Nations University-International Institute for Global Health, Jalan Yaacob Latiff, Kuala Lumpur, 56ooo, Mala

c University of Botswana, Private Bag 0022, Gaborone, Botswana

d Centre for Global Environmental Culture (CGEC), IUBAT University, Dhaka 1230, Bangladesh

e College of Business Administration (CBA), IUBAT University, Dhaka 1230, Bangladesh

$f$ Ministry of Public Works and Utilities, Betio, South Tarawa, Kiribati

$g$ College of Agricultural Sciences (CAS), IUBAT University, Dhaka 1230, Bangladesh

* Corresponding author. Email: dubeop@mopipi.ub.bw

\section{ABSTRACT}

Least developed countries (LDCs) face a myriad of challenges, such as extreme poverty and immense pressure on natural resources that increase vulnerability to all forms of hazards. A synthesis on Global Environmental Change (GEC) and Sustainable Development in LDCs conducted in 12 Asia Pacific LDCs, built capacity and facilitated the integration of cross-scale information from local to international levels, to produce comprehensive outputs for policy needs. The aim was to synthesize material on major climate-related hazards and disasters and environmental challenges facing these LDCs, key barriers to reducing disasters, and identify underlying causes of such barriers while highlighting potential contribution of traditional locally based practices to reducing vulnerability. The synthesis benefitted from documented historical data, local experience, and a systematic review of grey and scientific literature. Results point to increased frequency and intensity of climate extremes taking a toll on lives and property and that, coastal zone and marine ecosystems are poorly managed and threatened by climate change. Key barriers to reducing disaster risk include governance, technical, financial, cognitive and cultural factors. Indigenous knowledge systems and local experience have the potential to enhance coping mechanisms where integrated into policy frameworks. Innovative, locally based mechanisms could assist LDCs in harnessing this potential.

\section{KEYWORDS}

Asia-Pacific least developed countries, Capacity building, Climate extremes, Global environmental change, Indigenous knowledge, Marine and coastal zone management

DOI

https://doi.org/10.30852/sb.2017.108

\section{DATES}

Received: 3 August 2016

Published (online): 21 November 2017

Published (PDF): 9 May 2018

\section{INTRODUCTION}

The changing global environment is impacting sustainable development throughout the globe, with some of the worst impacts on LDCs. Of all the countries in the world, LDCs have the lowest Human Development Index ratings (UNDP, 2015). Several international frameworks have recognized the need for special treatment of LDCs, for example, the 2015 United Nations Framework Convention on Climate Change (UNFCCC) Paris Agreement and the Sendai Framework for Disaster Risk Reduction 2015-2030 (UN, 2015a; UNISDR, 2015). However, this recognition has not reduced the significant capacity constraints that result in acute susceptibility to disasters in these countries (Dube \& Sivakumar, 2015; UN, 2015b). Although vast information on global environmental change is generated at regional and international levels, policymakers in LDCs continue to rely on scanty and incomplete information, partly because available infor- 
mation lacks immediate local context for an effective application (Seitzinger et al., 2015).

The objective of this LDCs study was to synthesize material on major climate-related hazards and disasters and environmental challenges facing the Asia Pacific LDCs, key barriers to reducing climate disasters, and identify underlying causes of such barriers while highlighting potential contribution of traditional locally based practices to reducing vulnerability. In doing so the synthesis also sought to build capacity among scientists and policymakers in LDCs and facilitate the integration of local information with relevant GEC science outputs generated by various international organizations, to produce updated and consolidated outputs that can better address the challenges faced by LDCs. This study was conducted as part of the International Geosphere-Biosphere Programme (IGBP) second major international synthesis of key policy-relevant areas within GEC research from which a theme on GEC and Sustainable Development: Needs of LDCs was selected with a focus on the Asia Pacific (APAC) LDCs (Seitzinger et al., 2015).

\subsection{Asia Pacific LDCs}

There are 14 APAC LDCs, nine in Asia and five in the Pacific; among these are Small Island Developing States (SIDS). A significant proportion of APAC LDCs population live in degraded areas, for example, up to $39.3 \%$ in Cambodia in 2010, and under severe multidimensional poverty, e.g., 21\% in Bangladesh for the 2005-2014 period, which exacerbates vulnerability (UNDP, 2015). In general APAC LDCs lie along zones of potent hydro-meteorological hazards that have in recent years been enhanced by climate change (Dastagir, 2015). Together with high population growth, poor planning and inefficient management of resources, these events give rise to frequent disasters that have a potential for serious impacts on communities (IPCC, 2012). The APAC region accounted for $40 \%$ of all recorded global disasters from 2005 to 2014 (UN, 2016). APAC LDCs suffer high exposure to hazards and elevated risk from disasters; for example, Vanuatu, Bangladesh, Solomon Islands and Cambodia are among the top 15 most exposed countries worldwide (UNESCAP, 2015). Despite their vulnerability, APC LDCs have a great potential wealth of indigenous knowledge that has not been fully tapped to contribute towards addressing the vulnerability (Dewan, 2015; Basak et al, 2015; Rahman \& Rahman, 2015a; Jahan et al, 2017).

\section{METHODOLOGY}

The synthesis commenced in 2009 under the guidance of IGBP and targeted LDCs scientists through a wide consultative process within the IGBP community,

\section{HGHLIGHTS}

Asian LDCs suffer high exposure to hazards and elevated risk from disasters.

» Environmental changes impair key resources such as coastal and marine ecosystems.

» Weak governance systems and lack of focus on adaptive capacity needs are barriers.

» Indigenous adaptation mechanisms are potential solutions being lost or overlooked.

» Asian LDCs lack capacity for generating long term, up to date and locally relevant scientific information to guide policy.

its partners, and other regional and international environmental research initiatives. This culminated in a preliminary set of focus areas and a planning workshop in September 2010 from which the synthesis focus areas and participants were finalized and synthesis methodologies established.

The study covered drought, floods, coastal zone management and the marine environment, with a focus on barriers to reducing disaster risks and the potential of indigenous/local knowledge to minimize vulnerability. It extended over Bangladesh, Nepal, Bhutan, Afghanistan, Yemen, Myanmar, Cambodia, Lao PDR, Kiribati, Vanuatu, Solomon Islands and Samoa, as determined by the participating scientists who were at liberty to collaborate beyond APAC LDCs to enhance networking and build capacity.

The synthesis relied on building on existing knowledge and skills of LDCs scientists, shared experience, learning by doing, and training, for instance, on producing peer-reviewed publications (Dube \& Sivakumar, 2015). The primary data source was a literature review that assessed published and grey literature of theoretical and case studies, policy reviews and documented adaptation practices with some material from popular media. The document searches were conducted using various search strings relying on academic databases such as ISI Web of Knowledge, Elsevier, EBSCO, and Wiley. Whilst grey literature utilized Google Scholar, Google, ProQuest and also targeted websites e.g. specific websites related to LDC- SIDS and included consultation with experts (Kuruppu, \& Willie, 2015). In addition, direct linkages with the science community in the region and beyond through institutional visits, workshops, and seminars were made in different countries (IGBP, 2015). Informal meetings with various stakeholders including policy makers and selected community leaders and field observations were also used to gather data (Miah, 2015; Miyan, 2015). The data sourcing and communication techniques used facilitated cross-validation of sourced information and allowed synthesizing and integrating information 
established under different styles of knowledge creation, e.g., indigenous knowledge from a community, conventional scientific knowledge, and knowledge from practitioners. Details of protocols used to gather information are outlined in ten papers published in a special issue of the Journal of Weather and Climate Extremes volume 7, March 2015.

\section{RESULTS AND DISCUSSION}

The result of the efforts described in section 2 was interdisciplinary evidence produced from the 12 LDCs across geographic and temporal scales and of a cross-sectoral nature. A special issue of the journal Weather and Climate Extremes (Dube \& Sivakumar, 2015) and policy briefs in English and in one of the Bangladesh local languages were produced, and an information dissemination workshop communicated the final results to varied stakeholders (SADMC, 2015; SADMC \& IUBAT, 2015). These activities also served as a capacity-building process and formed a foundation for sustainability beyond the project. Key scientific findings of the synthesis established from assessing information from 12 LDCs follow below.

\subsection{Barriers to Reducing Climate-Enhanced Disaster}

\section{Risk}

The results on barriers to reducing climate-enhanced disaster risk showed that the most common barrier was governance, followed by technical, cognitive and cultural, and financial issues (Table 1; Kuruppu \& Willie, 2015). These barriers are products of interrelated processes and therefore solutions to these will be interlinked. The section below expands on these barriers and others under different themes, highlights needs and elucidates potential solutions.

\subsection{Drought}

Nearly all APAC LDCs experience frequent moderate-to-severe droughts of all types. For example, out of the 34 provinces in Afghanistan, 14 experienced drought conditions in 2011 which affected nearly 2.6 million people (Huffington Post, 2011). About $80 \%$ of APAC LDCs population depend on traditional agriculture. However, production of staples such as rice and wheat could decline by $8 \%$ and $32 \%$ respectively by 2050 due to drought (Miyan, 2015). Drought intensity is increasing, but the capacity to adapt is limited. Early awareness could reduce impacts, but drought forecasting and early warning are in their infancy because of lack of expertise and technology, as well as a scientific orientation that disregards

TABLE 1. Barriers to reducing climate-enhanced disaster risk (Kuruppu \& Willie, 2015)

Barrier

\section{Description of barriers}

\section{Governance}

Technical

Cognitive-cultural

Financial

Other
Governance from the local to the international level:

i. Poor coordination between the tiers of government constrains engagement between national adaptation efforts and Local Government limiting the role of communities. This was most common with externally driven adaptation brokered by regional agencies with external donors on behalf of national governments. Disaster risk reduction initiatives need to focus on empowering local leaders through a participatory process.

ii. Limited capacity to govern and fully engage international forums.

ii. Limited capacity to govern and fully engage international forums.

Limited data available on climate and other biophysical resources due to lacking capacity to generate and manage this data.

Failure to incorporate community traditional knowledge, rituals, cultural values and norms and religious believes. Several studies reported declining trend in traditional knowledge as a barrier to adaptive capacity.

International adaptation funding for LDCs is inadequate, unpredictable, complex to access and administer and inequitable. Limited in-country capacity to access and manage funds, e.g., in rural areas. Some LDCs SIDS, e.g., Tuvalu, found it difficult to compete with larger LDCs in accessing funding. A common theme was the inequalities in power relations between LDCs and donor countries. Capacity-building efforts are needed to address this persistent barrier.

The vulnerability of the major natural resources on which livelihoods were dependent, e.g., water, agriculture, biodiversity, fisheries and coastal zones. 
TABLE 2. Examples of potential traditional practices established mostly for Bangladesh for integrating with conventional approaches to reduce disaster risk in APAC LDCs (Basak, Basak, \& Rahman, 2015; Dewan, 2015; IGBP, 2015; Miyan, 2015; Rahman \& Rahman, 2015a,b; SADMC, 2015; SADMC \& IUBAT, 2015; Jahan et al, 2017).

\section{Traditional and/or local practices \\ Description potential traditional/local practices}

Forecasting heavy storms

Household level pre-flood preparations

Household level response to floods

Traditional Farming practices

Traditional Farming practices

\section{Water conservation}

Assessed clouds, intensity of thunderstorm and wind, extent of rainfall in upper catchments, position of stars, temperature and also behaviour of insects, birds and animals.

i. Built on elevated ground with multi-purpose ponds around the house that act as sources of portable water and for fish and aquaculture.

ii. Used protective windbreaks plants, e.g., coconut, areca nut and fishtail palm. However, traditional mud houses are vulnerable to destruction by floods.

iii. Food reserves, e.g., puff rice (Muri) and flat rice (Chira), for period of floods and also had measures for livestock.

i. "Vela" - a float used for transport during floods.

ii. Shelter from floods included "Matcha" - elevated surface made out of bamboo or woods - or relied on "Vela" to live on until safe.

iii. Medicinal e.g.s: green coconut water used to rehydrate the victims of waterborne diseases like diarrhoea, cholera and dysentery.

i. Adjusted crops and cropping with climate to reduce drought impacts.

ii. Practices such as permaculture, mulching, and traditional harrowing followed by powdering the soil to protect evaporation deserve to be documented and shared for wider practice.

iii. Rice known as "Jola Rice" has proved to be resilient to even severe floods.

i. Water reserves from rain water harvesting reduce heavy reliance on underground water, which lowered the groundwater table and increased the risk of arsenic contamination. Other water conservation approaches include traditional flood-plain management.

i. Adjusted crops and cropping with climate to reduce drought impacts.

ii. Practices such as permaculture, mulching, and traditional harrowing followed by powdering the soil to protect evaporation deserve to be documented and shared for wider practice.

iii. Rice known as "Jola Rice" has proved to be resilient to even severe floods. indigenous knowledge systems (Table 1 and 2). Climate modelling to better understand the Asian Monsoon in light of climate change and for different agro-ecological zones could support region-specific drought adaptation plans (Dastagir, 2015). Inter-country water protocols could help to reduce human-induced drought conditions. Measures such as the use of drought-resistant crop varieties, water-efficient irrigation systems, switching to dry-season cropping or in extreme cases tree crops, all need to be considered (Karim \& Rahman, 2015). Indigenous practices could fill some gaps, for instance in Vanuatu and Samoa traditional practices such as openly sharing crop varieties and maintaining the genetic material in reservoirs in farmers' fields help enhance adaptation to drought. While in the Solomon
Islands, erosion of traditional knowledge precluded the passing of this knowledge to the younger generations and consequently, increase in pests and disease of food crops was reported and this has led to heavy reliance on imported, processed foods (Kuruppu \& Willie, 2015). Overall, scientific information that is integrated with indigenous and local knowledge for longer timeframes is required for better responses to drought (Miyan, 2015; SADMC \& IUBAT, 2015).

\subsection{Floods}

All the APAC LDCs are affected by floods and historical data show that the scale, intensity, and duration of floods have increased. Bangladesh is a low-lying delta; combined with poor land use management, the 
result is that $80 \%$ of the country is affected by floods, causing millions to suffer every year, particularly the most vulnerable: nearly $32 \%$ of the total population of Bangladesh lives in slums (Dewan, 2015). Communities in APAC LDCs have been coping with flooding by using inherited wisdom and multi-generational practices that, for several reasons, including policies that downplay traditional knowledge systems, are rapidly being lost (Table 2).

\subsection{Coastal Zone and Marine Environment}

Government and NGOs in Bangladesh and Nepal have initiated a number of activities to minimize the adverse effects of floods, including flood forecasting and building awareness at the community level, training for preparedness and flood response, and assisting with emergency relief and post-flood rehabilitation. However, more regional forecasts are required and mandatory environmental impact assessments prior to construction of structures such as canals and water reservoirs, roads, and embankments could preserve natural water flows and reduce flood damage. The use of plants for flood control is constrained by reliance on non-adaptive exotic varieties (Table 2). Flood damage can be reduced by choosing plants according to the adaptation requirements of the species, corresponding to specific climate and physiographic conditions (Basak et.al. 2015).

An analysis of coastal infrastructure in the Bay of Bengal region, where over 50 million people reside, points to increased long-term waterlogging due to a combination of factors, including sea-level rise, increased tidal surges, cyclones, flooding, and erosion, which are linked to climate change and also poor coastal zone management (Vivekanandan et al., 2016). Withdrawal of water in upstream areas plus land degradation result in heavy siltation in the estuaries of the major rivers, the Ganges, Brahmaputra, and Meghna, negatively affecting fish productivity (Miah, 2015; Jahan et al., 2017). Poor maintenance and inadequate management of the polders have also contributed to internal drainage congestion and heavy external siltation. Further, investments in flood control in the form of embankments, roads, and highways block traditional navigation routes and water flows, and also have negative impacts on coastal zones. This is also the case with thick wind barriers that have been mounted along the coast, increasing the wind-speed and damaging the structures (Rahman and Rahman 2015a).

Although increased awareness has significantly reduced the death tolls during extreme events, practices noted above result from policies that are poorly informed by science and are not rooted in on-the-ground realities and lack community ownership (Dutta et al., 2016; Table
2). In this regard, the Forest Department in Bangladesh is considering a program of participatory mangrove plantation involving coastal communities.

Overall an integrated coastal policy involving the areas of rainwater harvesting, sanitation, controlled waterlogging, arsenic contamination, salinity, landslides, and erosion could contribute to the development of "smart" coastal cities that are more resilient to climate change-related hazards (Bajracharya et al., 2014; Rahman \& Rahman, 2015b).

\subsubsection{Fisheries and the Marine Environment}

Marine fisheries provide livelihoods to millions of people in the Bay of Bengal, accounting for about 4.4\% and $9.1 \%$ of the GDP in Bangladesh and Myanmar respectively (BOBLME, 2014). The Hilsa fishery is estimated to be worth over \$USD 2 billion for Bangladesh, India, and Myanmar (BOBLME, 2014). But the Catch per Unit Effort shows a decline of up to $50 \%$ in terms of fish available (Miah, 2015; Dutta et al., 2016; Jahan et al, 2017). This is due to several factors, including changes in the marine environment, such as warming, shifts in salinity and $\mathrm{pH}$ plus the wider problem of ocean acidification, sea level rise, and changing currents, upwelling, and water mass movement, occurring together with poor harvesting methods plus overexploitation and the ever-increasing water pollution (Miah, 2015; SADMC, 2015). Change of migration patterns of spawning, growth, and production results in catch trends shifting to deep seas, but the local industry is ill-equipped for deep-water fishing (IGBP, 2015; Vivekanandan et al., 2016). Better management and environment-friendly practices could significantly reduce pollution (Habib et al., 2014; FAO, 2016).

Bangladesh and Myanmar account for $50-60 \%$ and $20-25 \%$ of the global catch respectively for the most harvested species Hilsa, (Jahan et al, 2017). Mechanisms to reduce pressure on Hilsa could include harvesting nonconventional seafood, e.g., seaweed and other fish species, but these need to be investigated (Miah, 2015). In Bangladesh, the government has created policy initiatives such as the Hilsa Development Trust Fund for sustainable production of Hilsa, but implementation remains a challenge. In Myanmar, the government has pledged through international conventions to put $10 \%$ of its marine areas under protection by 2020, but this might be too little too late. Because there are many interlinkages to the fishery, an in-country multi-agency structure is needed to monitor the implementation of the national Hilsa management plans (BOBLME, 2014; Miah, 2015; SADMC, 2015; FAO, 2016).

\section{CONCLUSION}


Governments and the international community are making efforts to reduce disaster risk in LDCs. However, country-level studies on extreme events for forecasting, early warning, and mitigation processes are required. Several barriers to adaptation that have a bearing on both national and international policy frameworks were identified. One major barrier was weak governance resulting in inadequate engagement of local governments and communities due partly to modalities of external funding and uninformed policies (Habib et al., 2014; Kuruppu, \& Willie, 2015; Dutta et al., 2016). This results in failure to adequately incorporate cultural knowledge and local practices in plans to reduce disaster risk (Jahan et al, 2017).

Adaptation and disaster risk reduction need to be anchored on local conditions, experiences and traditional knowledge about extreme events such as drought and floods as well as coastal zone management and the marine environment (Jahan et al, 2017). To this end, it was demonstrated that most APAC LDCs have very strong local/traditional knowledge to combat disasters and manage environmental resources that are yet to be tapped (Table 2). By highlighting this, the synthesis has opened up scope for new research, e.g., regarding integration of traditional and conventional practices for long-term solutions to environmental change and how these can inform broader processes such as the 2030 Agenda for Sustainable Development. External support to supplement the limited financial and technical capabilities of LDCs will be valuable in advancing the noted research avenues. Moreover, the synthesis work also highlighted the pertinence for greater engagement and long-term support in building the capacities of local APAC LDCs scientists to lead and co-produce locally relevant information to support policy.

\section{ACKNOWLEDGEMENT}

Financial support was secured from the Asia-Pacific Networks for Global Change Research (APN) through the International Geosphere-Biosphere Programme (IGBP). Support also came from the IGBP Regional Office in Brazil. Sincere thanks go to Dr Opha Pauline Dube for initiating this synthesis and leadership under the IGBP Secretariat, in particular, Dr João Marais and Dr Karen Smyth. Dr Mannava Sivakumar is acknowledged for guidance with the special issue and Naomi Lubick for language editing. Sincere gratitude goes to the deceased Professor M Alimullah Miyan, former Chairperson of SADMC, founder and Vice Chancellor of IUBAT University (Bangladesh) who led the Asian LDC part of this IGBP/ APN synthesis with such great enthusiasm, communicating the project in various forums locally-regionally and internationally while mentoring and providing material support to the participating researchers. Professor Alimullah Miyan's contribution from the proposal development stage through the life of the synthesis was pivotal to the success of the project - may his soul rest in peace. The synthesis authors are indebted to the various stakeholders who volunteered their time and information.

\section{REFERENCES}

Bajracharya, B., Cattell, D., \& Khanjanasthiti, I. (May 2014). Challenges and Opportunities to Develop a Smart City: A Case Study of Gold Coast, Australia. Paper presented at Real CORP 2014: Plan it Smart, Vienna, Austria. http://epublications.bond.edu.au/ fsd_papers/16/

Basak, S. R., Basak, A. C., \& Rahman, M. A. (2015). Impacts of floods on forest trees and their coping strategies in Bangladesh. Weather and Climate Extremes, 7, 43-48. doi:10.1016/j.wace.2014.12.002

BOBLME (2014) Assessing, demonstrating and capturing the economic value of marine and coastal ecosystem services in the Bay of Bengal Large Marine Ecosystem BOBLME -2014 - Socioec-02.

Dastagir, W.R. (2015). Modeling recent climate change induced extreme events in Bangladesh: A review. Weather and Climate Extremes, 7, 49-60.

Dewan, T. H. (2015). Societal impacts and vulnerability to floods in Bangladesh and Nepal. Weather and Climate Extremes, 7, 36-42. http://www.sciencedirect.com/ science/article/pii/S2212094714000930

Dube, O. P., \& Sivakumar, M.V.K. (2015). Global environmental change and vulnerability of Least Developed Countries to extreme events: Editorial on the special issue. Weather and Climate Extremes, 7, 2-7.

Dutta S. Chakraborty, K. and Hazra S. (2016). The Status of the Marine Fisheries of West Bengal Coast of the Northern Bay of Bengal and Its Management Options: A Review. Proceedings of the Zoological Society June 2016, 69 (1), pp 1-8.

FAO (2016). Final evaluation of Sustainable Management of the Bay of Bengal Large Marine Ecosystem (BOBLME) project February 2016 http://www.fao. org/3/a-bd470e.pdf

Habib, A., Ullah, Md. H., Duy, N.G. (2014). Bioeconomics of Commercial Marine Fisheries of Bay of Bengal: Status and Direction. Economics Research International, Volume 2014, Article ID 538074, 10 pages. http://dx.doi.org/10.1155/2014/538074.

Huffington Post (2011) Afghanistan Faces Drought, Hunger (http://www.huffingtonpost. com/2011/12/03/afghanistan-drought_n_1127029. 
html accessed in October 2013).

IGBP (2015). An International Geosphere-Biosphere Programme Synthesis Theme on Global Environment Change and Sustainable Development: Needs of Least Developed Countries. Final Report submitted to APN. Stockholm: IGBP Secretariat. 95 pp. https:// www.apn-gcr.org/resources/files/original/23deef4af16133ad47a1025f116eea66.pdf

IPCC (2012). Managing the Risks of Extreme Events and Disasters to Advance Climate Change Adaptation: Special Report of the Intergovernmental Panel on Climate Change (IPCC) 2012: Contributing Author IPCC Working Group II. Cambridge: Cambridge University Press. ISBN 978-1-107-025006-6. www. cambridge.org/978117607804

Jahan, I., Ahsan, D. and Farque, Md H. (2017). Fishers' local knowledge on the impact of climate change and anthropogenic interferences on Hilsa fishery in South Asia: evidence from Bangladesh. Environ Dev Sustain.19, 461-478. DOI 10.1007/s10668-0159740-0

Karim Md. R., Rahman M.A. (2015). Drought risk management for increased cereal production in Asian Least Developed Countries. Weather and Climate Extremes, 7, 24-35.

Kuruppu, N., \& Willie, R. (2015). Barriers to reducing climate enhanced disaster risks at Least Developed Country-Small Islands through anticipatory adaptation. Weather and Climate Extremes, 7, 72-83.

Miah, M. S. (2015). Climatic and anthropogenic factors changing spawning pattern and production zone of Hilsa fishery in the Bay of Bengal. Weather and Climate Extremes, 7, 109-115.

Miyan, M. A. (2015). Droughts in Asian Least Developed Countries: Vulnerability and sustainability. Weather and Climate Extremes, 7, 8-23.

Rahman, M. A., \& Rahman, S. (2015a). Natural and traditional defense mechanisms to reduce climate risks in coastal zones of Bangladesh. Weather and Climate Extremes, 7, 84-95.

Rahman, S., \& Rahman, M. A. (2015b). Climate extremes and challenges to infrastructure development in coastal cities in Bangladesh. Weather and Climate Extremes, 7, 96-108.

SADMC (2015). Proceedings of the Information Dissemination Workshop on Global Environment Change and Sustainable Development: Needs of Least Developed Countries. September 20-21, 2015. IGBP/APN and South Asian Disaster Management Centre, IUBATInternational University of Business Agriculture and Technology, Dhaka (Bangladesh). 14 pp.

SADMC \& IUBAT (2015). Policy Brief on Sustainable Development in Bangladesh: Facing Global Environ- mental Change. Bangladesh: South Asian Disaster Management Centre, IUBAT University. ISBN 978984-33-9805-5

Seitzinger, S.P., Gaffney, O., Brasseur, G., Broadgate, W., Ciais, P., Claussen, M., Erisman, J.W., Kiefer, T., Lancelot, C., Monks, P.S., Smyth, K., Syvitski, J. \& Uematsu, M. (2015). International Geosphere-Biosphere Programme and Earth system science: Three decades of co-evolution. Anthropocene, 12, 3-16.

UN (2015a). Paris Agreement. United National Framework Convention for Climate Change (UNFCCC) 21 Conference of Parties (COP21).

UN (2015b). Asia-Pacific Countries with Special Needs Development Report 2015. United Nations Economic and Social Commission for Asia and the Pacific (ESCAP). 112 pp.

UN (2016). Disasters without Borders. Regional Resilience for Sustainable Development. Asia-Pacific Disaster Report 2015. United Nations Economic and Social Commission for Asia and the Pacific (ESCAP). $193 \mathrm{pp}$.

UNDP (2015). Human Development Report 2015: Work for Human Development. New York, NY: United Nations Development Programme (UNDP). ISBN: 978-92-1-126398-5. 274 pp.

UNESCAP (2015). Overview of Natural Disasters and their Impacts in Asia and the Pacific, 1970 - 2014.ESCAP Technical Paper Information and Communications Technology and Disaster Risk Reduction Division. 30 pp.

UNISDR. (2015). The Sendai Framework for Disaster Risk Reduction 2015-2030. Geneva: United Nations Office for Disaster Risk Reduction. 37 pp.

Vivekanandan, E., Hermes R. and O'Brien, C. (2016). Climate change effects in the Bay of Bengal Large Marine Ecosystem. Environmental Development, 17, 46-56. https://doi.org/10.1016/j.envdev.2015.09.005 